\title{
A Simplified Method for Estimating Atomic Number and Neutrons Numbers of Elements Based on Period and Group Numbers in the Periodic Table
}

\author{
LAITH H. M. AL-OSSMI ${ }^{1}$ and ALI K. AL-ASADI ${ }^{2}$ \\ ${ }^{1}$ College of Engineering, University of Thi-qar, Al-nassiriya city, Iraq. \\ ${ }^{2}$ College of Engineering, University of Sumer, Rifai city, Iraq. \\ ${ }^{*}$ Corresponding author E-mail: hardmanquanny @ gmail.com \\ http://dx.doi.org/10.13005/ojc/350104
}

(Received: December 01, 2018; Accepted: January 25, 2019)

\begin{abstract}
This research has proposed formulas, in which the atomic number and neutron numbers to any element in the periodic table are determined according to element position in the periodic table. These formulas have been arranged to fit with periodic system of elements in the IUPAC's Periodic Table. The main outcome is to introduce layout regularity, which may reflect the regularity of the periodic law more faithfully. In this research, atomic number to any element in the periodic table is predictably calculated by the group and period numbers which were displayed into 7 Periods horizontally, and 18 Groups vertically, determining and dispensing altogether the elements positions at the periodic system. Application of these proposed formulas showed linearity from has good agreement with these separated elements of Lanthanum in the f-block elements (Lanthanides and Actinides), which were in no interruptions in the sequence of increasing atomic numbers. In addition, the relationship of the f-block to the other blocks of the periodic table also becomes easier to see. In addition, the formulas are extensible to expanding future table and allowed determining the atomic number of the future elements starting from 119 till the element of 136 , at the main body of the periodic table, and can be used as a simple and alternative method for determine the numbers of atomic and neutron in the IUPAC's Periodic Table.
\end{abstract}

\section{INTRODUCTION}

The periodic table is a masterpiece of organised chemical information. However, there no one single or best structure for the periodic table, but most standard form of chemistry's periodic table is the current form of the IUPAC's. There was not a really advanced step till the 1869 when Russian chemistry professor Dmitri Mendeleev achieved a revolutionary improvement in the main body of the periodic table of elements. Mendeleev published his tabulated element in a paper in which he drawn a tabular arrangement of the chemical elements as each the 63 known elements were arranged in groups according to their properties ${ }^{1}$ (Bent, and Weinhold, 2007), this step allowed him to recognize that there is a clear pattern in which the elements were columned whenever the atomic mass number

This is an Open Access article licensed under a Creative Commons license: Attribution 4.0 International (CC- BY). Published by Oriental Scientific Publishing Company @ 2018 
was decreased ${ }^{6,7}$ (IUPAC, 2015; Kaji, 2004). However, Mendeleev left gaps in his table whenever he did not found the suitable elements to fill these gaps, thus he was able to have predictions about the properties to the missed elements, and he also gave detailed predictions for the properties of elements he had earlier noted were missing, but should exist.

The first outcomes from Mendeleev's table came in 1875 when Gallium element was discovered to fill the gap 7,5 according to predicted properties predicted by Mendeleev's table, later Germanium and Scandium elements also proved the Mendeleev's table predictions filling the gaps (Kaji, 2004; Hinrichs, 2017). In 1913, the second revolutionary improvement in the periodic table achieved by Henry Moseley, by rearranging the table according to increasing in the atomic number instead the previous indication of the atomic mass number ${ }^{8}$ (Karol, 2002; Kaji, 2004). Moseley's table was internationally adopted as it allowed successfully adding all current and these new discovered elements with their predicted properties, and his organization of the periodic table can be used to derive relationships between the various element properties, but also the predicted chemical properties and behaviours of undiscovered or newly synthesized elements. More advanced development was added to the periodic table by Glenn Seaborg, an American scientist. In 1945 Seaborg made the suggestion that the actinide elements, like the lanthanides, were filling an sub-level ${ }^{9}$ (Bent, and Weinhold, 2007; Koppenol, 2002). Seaborg's suggestion was found to be correct and he subsequently went on to win the 1951 Nobel Prize in chemistry for his work in synthesizing actinide elements $^{12}$ (Gorin,1996; Hinrichs, 2017). In 2010, a joint Russia-US collaboration claimed to have synthesized six atoms of element 117 (Tennessine) ${ }^{11}$ (Gordin, 2004), making it the most recently claimed discovery.

The periodic table is arranged in order of atomic number. The atomic number is usually in the top left or top right corner of the element's box, but it could be in a different spot. This is always a whole number. An element's atomic number is the number of protons in the nucleus of a single atom of that element $^{12,13}$ (Orlando, 2000; Siegfried, 2002).

The atomic number of an element or isotope cannot change, so it can use the atomic number to help figure out other characteristics, such as the number of electrons and neutrons in an atom. Therefore it can be concluded that this is the fundamental definition of an element as the number of protons determines the total electric charge of the nucleus, which determines how many electrons the atom can support. Because electrons are responsible for almost all chemical interactions ${ }^{11}$ (Niaz, 2004), the atomic number indirectly sets almost all of the element's physical and chemical properties. Some scientists prefer the term "relative atomic mass" instead of atomic weight ${ }^{1}$ (Ben-Zvi, \& Genut,1989). The mass number is the total number of protons and neutrons in one atom of an element. This is easy to find: just take the atomic weight printed on the periodic table, and round to the nearest whole number ${ }^{14}$ (Russo \& Silver, 2002). However, using the atomic weight means getting an average for a typical sample. A Bromine sample has an average mass number of 80 , but as it turns out, a single Bromine atom almost always has a mass number of 79 or $8^{16,13}$ (IUPAC, 2015; Silberberg, 2006). Therefore it can be concluded that the atomic number is consequently the number of protons in an atom of an element.

Also, this obviously tells us that an atom protons in its nucleus. Therefore, calculation the number of neutrons can be gotten by subtracting the atomic number from the mass number. Thus, the mass number is a count of the number of particles in an atom's nucleus. In general, the nucleus is made up of protons and neutrons. So, the interesting thing here is that it can be written as demonstrated in formula $a^{6}$ (IUPAC, 2015):

Mass Number $=($ Number of Protons $)+($ Number of Neutrons)

If it is known how many protons element has, it could figure out how many neutrons it has. The adding or removing neutrons from an atom does not create a different element. Rather, it creates a heavier or lighter version of that element, which are called isotopes ${ }^{10}$ ( McMurry \& Fay, 2001), and most elements are actually a mixture of different isotopes. Building on the previous discussion, the Atomic Number can be linked with the Mass Number and the Number of Neutrons by different connections as the following: 
Mass Number $=($ Atomic Number $)+($ Number of Neutrons)

Number of Neutrons $=$ (Mass Number) $-($ Atomic Number)

In this research, the Atomic Number is identified by using this technique discussed in forms b\&c. In order to determine the Atomic Number of each element at any part of the periodic table, 17 formulas were developed in this research depending on the number of Periods (rows) and Groups (columns), which are depicted according to the periodic table.

\section{MATERIALS AND METHODS}

The research is design to deal with the current periodic table, without any change in the arrangement of elements that vertically presents the periods, and horizontally the groups systemized in the IUPAC's table.
As depicted in the periodic table, 7 rows (Periods) are divided horizontally, whereas at the columns (Groups), elements were vertically listed within 18 columns. According to period's number and group's number, this research tried to build leaner formulas to determine both the Atomic and Neutrons Numbers to any element in the periodic table. To obtain the Mass Number, the researcher rounded the atomic weight to the nearest whole number for 118 elements.

\section{Outcomes of formulas}

As mentioned earlier, the IUPAC's periodic table is consisted from 118 elements into 18 Groups $(G)$, and 7 Periods (P), as depicted in Fig. 1. Therefore, table view with all properties \& details of their accumulated elements are used in this research. Graphically, Fig. 1 detailed this arrangement in the IUPAC's periodic table, as following.

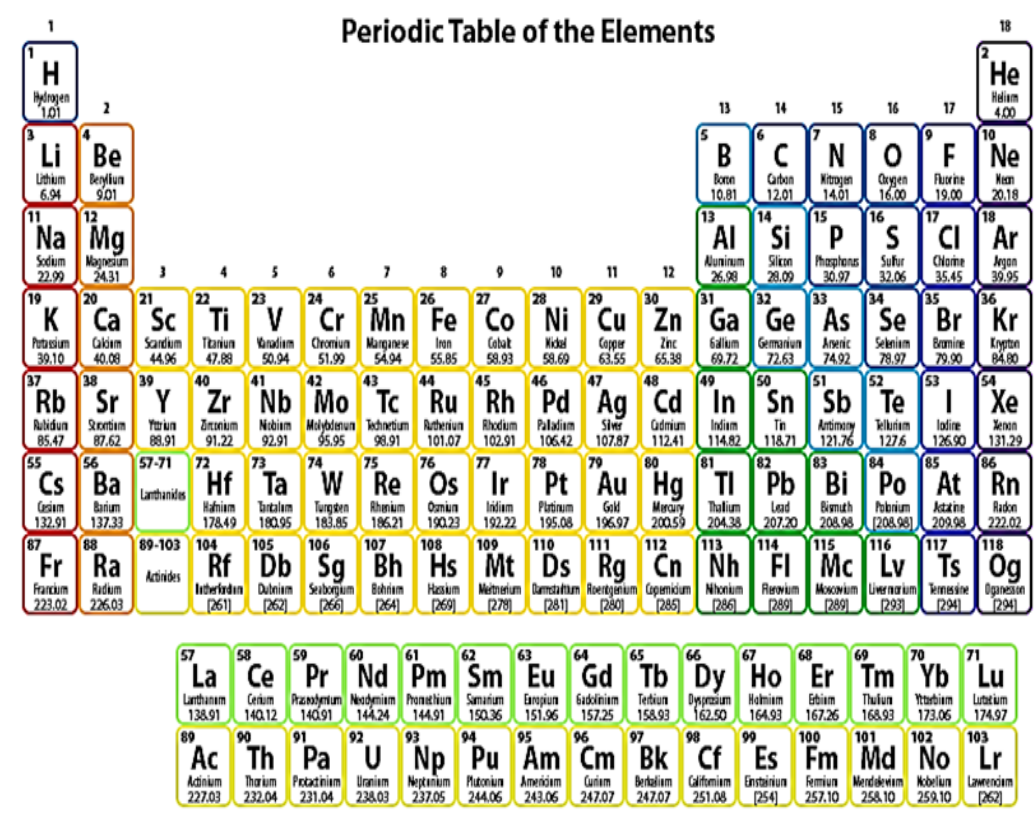

Fig. 1. Typical periodic table and details of its accumulated elements (IUPAC, 2015)

Building on the elements tabulated in Fig. 1, there are 18 columns (Groups), and 7 rows (periods) in the periodic table accumulate 118 elements. For example Hydrogen is located in Group 1 and Period 1 , whereas Thallium is located in Group 13 and Period 6. Also, Lanthanides and Actinides splitting down the central body of the table at Periods 6 and 7, and snapped with Group 3. Thus, elements from (57 till 71), are located in period 6 and Groups
(3 till 17), whereas elements from (89 till 103), are located down at Groups (3 till 17). Consequently, there is a relationship between the Atomic number and the Period and Groups' number in the periodic table through which we can produce simple equations to obtain the atomic number to any element at the periodic table if we have its period and group number. From this point, this research has listed these formulas which can be used to predict the atomic 
number to any element according to its position's number of period and group. Table 1 detailed these 118 elements in the periodic table according to their period and group numbers.

Table 1: Details of elements accumulated in the periodic table

\begin{tabular}{lcc}
\hline No. Elements & Group & Period \\
& $(1,2,3,4,5,6,7,8,9,10$, & $(1,2,3,4,5,6 \& 7)$ \\
& $11,12,13,14,15,16,17, \& 18)$ &
\end{tabular}

\begin{tabular}{|c|c|c|c|}
\hline 1 & $\mathrm{H}$ & 1 & 1 \\
\hline 2 & $\mathrm{He}$ & 12 & 1 \\
\hline 3 & $\mathrm{Li}$ & 1 & 2 \\
\hline 4 & $\mathrm{Be}$ & 2 & 2 \\
\hline 5 & B & 12 & 2 \\
\hline 6 & $\mathrm{C}$ & 12 & 2 \\
\hline 7 & $\mathrm{~N}$ & 12 & 2 \\
\hline 8 & $\mathrm{O}$ & 12 & 2 \\
\hline 9 & $F$ & 12 & 2 \\
\hline 10 & $\mathrm{Ne}$ & 12 & 2 \\
\hline 11 & $\mathrm{Na}$ & 1 & 3 \\
\hline 12 & $\mathrm{Mg}$ & 2 & 3 \\
\hline 13 & $\mathrm{Al}$ & 12 & 3 \\
\hline 14 & $\mathrm{Si}$ & 12 & 3 \\
\hline 15 & $\mathrm{P}$ & 12 & 3 \\
\hline 16 & $S$ & 12 & 3 \\
\hline 17 & $\mathrm{Ci}$ & 12 & 3 \\
\hline 18 & $\mathrm{Ar}$ & 12 & 3 \\
\hline 19 & $\mathrm{~K}$ & 1 & 4 \\
\hline 20 & $\mathrm{Ca}$ & 2 & 4 \\
\hline 21 & Sc & 3 & 4 \\
\hline 22 & $\mathrm{Ti}$ & 4 & 4 \\
\hline 23 & V & 5 & 4 \\
\hline 24 & $\mathrm{Cr}$ & 6 & 4 \\
\hline 25 & $\mathrm{Mn}$ & 7 & 4 \\
\hline 26 & $\mathrm{Fe}$ & 8 & 4 \\
\hline 27 & Co & 9 & 4 \\
\hline 28 & $\mathrm{Ni}$ & 10 & 4 \\
\hline 29 & $\mathrm{Cu}$ & 11 & 4 \\
\hline 30 & $\mathrm{Zn}$ & 12 & 4 \\
\hline 31 & $\mathrm{Ga}$ & 12 & 4 \\
\hline 32 & $\mathrm{Ge}$ & 12 & 4 \\
\hline 33 & As & 12 & 4 \\
\hline 34 & $\mathrm{Se}$ & 12 & 4 \\
\hline 35 & $\mathrm{Br}$ & 12 & 4 \\
\hline 36 & $\mathrm{Kr}$ & 12 & 4 \\
\hline 37 & $\mathrm{Rb}$ & 1 & 5 \\
\hline 38 & $\mathrm{Sr}$ & 2 & 5 \\
\hline 39 & $Y$ & 3 & 5 \\
\hline 40 & $\mathrm{Zr}$ & 4 & 5 \\
\hline 41 & $\mathrm{Nb}$ & 5 & 5 \\
\hline 42 & Mo & 6 & 5 \\
\hline 43 & Tc & 7 & 5 \\
\hline 44 & $\mathrm{Ru}$ & 8 & 5 \\
\hline 45 & $\mathrm{Rh}$ & 9 & 5 \\
\hline 46 & $\mathrm{Pd}$ & 10 & 5 \\
\hline 47 & $\mathrm{Ag}$ & 11 & 5 \\
\hline 48 & $\mathrm{Cd}$ & 12 & 5 \\
\hline 49 & In & 12 & 5 \\
\hline 50 & Sn & 12 & 5 \\
\hline 51 & $\mathrm{Sb}$ & 12 & 5 \\
\hline 52 & $\mathrm{Te}$ & 12 & 5 \\
\hline 53 & I & 12 & 5 \\
\hline 54 & $\mathrm{Xe}$ & 12 & 5 \\
\hline 55 & Cs & 1 & 6 \\
\hline 56 & $\mathrm{Ba}$ & 2 & 6 \\
\hline 57 & $\mathrm{La}$ & 3 & 6 \\
\hline 58 & $\mathrm{Ca}$ & 3 & 6 \\
\hline 59 & $\mathrm{Pr}$ & 3 & 6 \\
\hline 60 & $\mathrm{Nd}$ & 3 & 6 \\
\hline 61 & $\mathrm{Pm}$ & 3 & 6 \\
\hline 62 & $\mathrm{Sm}$ & 3 & 6 \\
\hline
\end{tabular}

\begin{tabular}{|c|c|c|c|}
\hline 63 & $\mathrm{Eu}$ & 3 & 6 \\
\hline 64 & $\mathrm{Gd}$ & 3 & 6 \\
\hline 65 & $\mathrm{~Tb}$ & 3 & 6 \\
\hline 66 & Dy & 3 & 6 \\
\hline 67 & Ho & 3 & 6 \\
\hline 68 & $\mathrm{Er}$ & 3 & 6 \\
\hline 69 & $\mathrm{Tm}$ & 3 & 6 \\
\hline 70 & $\mathrm{Yb}$ & 3 & 6 \\
\hline 71 & Lu & 3 & 6 \\
\hline 72 & $\mathrm{Hf}$ & 4 & 6 \\
\hline 73 & $\mathrm{Ta}$ & 5 & 6 \\
\hline 74 & W & 6 & 6 \\
\hline 75 & $\operatorname{Re}$ & 7 & 6 \\
\hline 76 & Os & 8 & 6 \\
\hline 77 & Ir & 9 & 6 \\
\hline 78 & $\mathrm{Pt}$ & 10 & 6 \\
\hline 79 & $\mathrm{Au}$ & 11 & 6 \\
\hline 80 & $\mathrm{Hg}$ & 12 & 6 \\
\hline 81 & $\mathrm{Ti}$ & 12 & 6 \\
\hline 82 & $\mathrm{~Pb}$ & 12 & 6 \\
\hline 83 & $\mathrm{Bi}$ & 12 & 6 \\
\hline 84 & Po & 12 & 6 \\
\hline 85 & At & 12 & 6 \\
\hline 86 & $\mathrm{Rn}$ & 12 & 6 \\
\hline 87 & $\mathrm{Fr}$ & 1 & 7 \\
\hline 88 & $\mathrm{Ra}$ & 2 & 7 \\
\hline 89 & $A c$ & 3 & 7 \\
\hline 90 & Th & 3 & 7 \\
\hline 91 & $\mathrm{~Pa}$ & 3 & 7 \\
\hline 92 & U & 3 & 7 \\
\hline 93 & $\mathrm{~Np}$ & 3 & 7 \\
\hline 94 & $\mathrm{Pu}$ & 3 & 7 \\
\hline 95 & Am & 3 & 7 \\
\hline 96 & $\mathrm{Cm}$ & 3 & 7 \\
\hline 97 & $\mathrm{Bk}$ & 3 & 7 \\
\hline 98 & Cf & 3 & 7 \\
\hline 99 & Es & 3 & 7 \\
\hline 100 & $\mathrm{Fm}$ & 3 & 7 \\
\hline 101 & $\mathrm{Md}$ & 3 & 7 \\
\hline 102 & No & 3 & 7 \\
\hline 103 & $\mathrm{Lr}$ & 3 & 7 \\
\hline 104 & Rf & 4 & 7 \\
\hline 105 & $\mathrm{Db}$ & 5 & 7 \\
\hline 106 & $\mathrm{Sg}$ & 6 & 7 \\
\hline 107 & $\mathrm{Bh}$ & 7 & 7 \\
\hline 108 & $\mathrm{Hs}$ & 8 & 7 \\
\hline 109 & Mt & 9 & 7 \\
\hline 110 & Ds & 10 & 7 \\
\hline 111 & $\mathrm{Rg}$ & 11 & 7 \\
\hline 112 & $\mathrm{Cn}$ & 12 & 7 \\
\hline 113 & $\mathrm{Nh}$ & 12 & 7 \\
\hline 114 & $\mathrm{Fi}$ & 12 & 7 \\
\hline 115 & Mc & 12 & 7 \\
\hline 116 & Lv & 12 & 7 \\
\hline 117 & Ts & 12 & 7 \\
\hline 118 & $\mathrm{Og}$ & 12 & 7 \\
\hline
\end{tabular}

\section{Calculation of atomic number}

In order to determine the atomic number of each element at any part of the table, this research adopt 17 formulas depend on the number of Periods $(P)$, and Groups $(P)$ at which the element is located as depicted in Table 1. In this research, regulation steps were adopted to identify the atomic number according to the period and group number, as following:

- In order to determine the Atomic Number to any element in the periodic table, it can be 
determined according to the Period $(P)$ and Group (G) numbers by using the following stapes and formulas:

- Get an element.

- $\quad$ Find your element's Period's \& Group's number on the periodic table.

1- If the element is located at the Period $1 \&$ Group 1, the Atomic Number can be found by:

(Atomic Number $=\mathrm{G}=\mathrm{P}$ )

2- $\quad$ If the element is located at the Period $1 \&$ Group 18, the Atomic Number can be found by:

(Atomic Number $=P+1)$

3- If the element is located at the Period 2 \& Group (1 or 2), the Atomic Number can be found by:

(Atomic Number $=\mathrm{G}+\mathrm{P}$ )

4- If the element is located at the Period 2 \& Group 13, the Atomic Number can be found by:

(Atomic Number $=\mathrm{P}+3$ )

(4) 14- If the element is located at the Period 6

Group 14, the Atomic Number can be found by:

$($ Atomic Number $)=P+4)$

(5) (Atomic Number $=\mathrm{G}+54$ )

6- If the element is located at the Period 2 \& Group 15, the Atomic Number can be found by:

(Atomic Number $=\mathrm{P}+5$ )

7- $\quad$ If the element is located at the Period 2 \& Group 16, the Atomic Number can be found by:

(Atomic Number $=\mathrm{P}+6$ )

8- If the element is located at the Period 2 \&

Group 17, the atomic number (D) can be found by:

(Atomic Number $=\mathrm{P}+7$ )

9- If the element is located at the Period 2 \&

Group 18, the atomic number (D) can be found by: and Groups (elements from 57 till 71). The Atomic Number to elements, (included Lanthanides), can be found by:

(Atomic Number $=\mathrm{P}+8$ )

10- If the element is located at the Period 3 \& Group (1 or 2), the Atomic Number can be found by:

(Atomic Number $=\mathrm{G}+10$ )

11- If the element is located at the Period 3 \& Group (from 13 till 18), the Atomic Number can be found by:

(Atomic Number $=\mathrm{G}$ )

12- If the element is located at the Period 4 \& Group (from 1 till 18), the Atomic Number can be found by:

(Atomic Number $=\mathrm{G}+18$ )

13- If the element is located at the Period 5 \& Group (from 1 till 18), the Atomic Number can be found by:

(Atomic Number $=\mathrm{G}+36$ )

Whereas, at the Period 6 \& Groups starting from 4 till 18, (these elements starting from 72 till $86, \mathrm{Hf}$ till $\mathrm{Rn})$, Atomic Number can be found by:

(Atomic Number $=\mathrm{G}+68$ )

15- If the element is located at the Period 7, the Atomic Number to elements, starting from 87 till 103 (included Actinides), can be found by:

(Atomic Number $=\mathrm{G}+86$ )

16- If the element is located at the Period 7 \& Group starting from 4 till 18 (these elements from 104 till 118), the Atomic Number can be found by:

(Atomic Number $=\mathrm{G}+100$ ) 
Therefore it can be concluded that elements after element Og , (starting from element number 119 till element number 136) will fit with the formula of $(G+118)$, whereas elements after numbers 136 will use formula of $(G+136)$ to determine their Atomic numbers and the Neutrons Numbers.

Although, the majority of elements exist as isotopes, isotopes have the same number of protons but they vary in the numbers of neutrons. However, a nucleus of each chemical element consists of protons, neutrons and electrons. The mass number of an element refers to the sum of the number of protons and neutrons. Note that the atomic number is equivalent to the number of protons as well as to the number of electrons.

Building on the relationship of Atomic Number, which links between Mass Number, and Number of Neutrons, it is easy to link it with the formulas obtained in this research, as following:

For any element:

Mass Number $=($ Atomic Number $)+($ Number of Neutrons)

Therefore, to find the mass number, the researcher rounded the atomic weight to the nearest whole number. For example, Bromine belongs to the group of halogens and exists as two isotopes having 44 and 46 neutrons. However, the neutral atom of Bromine has 35 electrons because the number of electrons equals the number of protons. Bromine's mass number is 80 since its atomic weight, 79.904, rounded up to 80 , and Bromine is located in the periodic table at Period 4 \& Group 17. Consequently, the Bromine's Atomic Number can be obtained by formula No. 12. Thus, 45 is the number of neutrons in an atom of Bromine. For Bromine element:

G+18 = Since, Bromine's Atomic Number

Therefore, Bromine's Number of Neutrons $=80-$ $(17+18)=45$

Bromine's Number of Electrons $=$ Atomic Number $=$ $\mathrm{G}+18=17+18=35$

Also, Silver is located in the period table at Period 5 \& Group 11, and a mass number of 107.863 , rounded up to 108. The Silver's Atomic Number can be obtained by formula No. 13. Therefore it can be concluded that 133 is the number of neutrons in an atom of Silver. For Silver element:

G+36 = Since, Silver's Atomic Number

Therefore, Silver's Number of Neutrons $=108-$ $(11+36)=133$

Silver's Number of Electrons $=$ Atomic Number $=$ $\mathrm{G}+36=11+36=47$

As described in previous examples, estimation of Atomic Number, Electrons Number and Neutrons numbers sensitivity to periods and group numbers were conducted by counting obtained 17 formulas exposed to different positions of elements in the periodic table. The Atomic Number, Electrons Number and Neutrons Numbers of elements have been calculated as depicted in Table 2. Also, table 2 shows this application implemented on samples of 118 elements accumulated in the periodic table.

Table 2: Formulas to determine Atomic, Neutrons numbers of elements in the periodic table

\begin{tabular}{cccccc}
\hline Elements & Period & Group & $\begin{array}{c}\text { Atomic Number, } \\
\text { Electrons Number }\end{array}$ & Mass Number* & Neutrons Number** $^{\star *}$ \\
\hline $\mathrm{H}$ & 1 & 1 & $\mathrm{G}, \mathrm{P}$ & 1 & $0^{\wedge}$ \\
$\mathrm{He}$ & 1 & 18 & $\mathrm{P}+1$ & 4 & $4-(\mathrm{P}+1)$ \\
$\mathrm{Li}$ & 2 & 1 & $\mathrm{P}+1, \mathrm{P}+\mathrm{G}, \mathrm{G}+2$ & 7 & $7-(\mathrm{P}+1)$ \\
$\mathrm{Be}$ & 2 & 2 & $\mathrm{P}+\mathrm{G}, \mathrm{P})^{2}, \mathrm{G}$ & 9 \\
$\mathrm{~B}$ & 2 & 13 & $\mathrm{P}+3$ & 92 \\
$\mathrm{C}$ & 2 & 14 & $\mathrm{P}+4$ & 11 & $11-(\mathrm{P}+3)$ \\
$\mathrm{N}$ & 2 & 15 & $\mathrm{P}+5$ & 12 & $12-(\mathrm{P}+4)$ \\
$\mathrm{O}$ & 2 & 16 & $\mathrm{P}+6$ & 14 & $14-(\mathrm{P}+5)$ \\
$\mathrm{F}$ & 2 & 17 & $\mathrm{P}+7$ & 16 & $16-(\mathrm{P}+6)$ \\
$\mathrm{Ne}$ & 2 & 18 & $\mathrm{P}+8$ & 20 & $20-(\mathrm{P}+7)$ \\
$\mathrm{Na}$ & 3 & 1 & $\mathrm{G}+10$ & 23 & $23-(\mathrm{G}+10)$ \\
$\mathrm{Mg}$ & 3 & 2 & $\mathrm{G}+10$ & 24 & $24-(\mathrm{G}+10)$ \\
$\mathrm{Al}$ & 3 & 13 & $\mathrm{G}$ & 27 & $27-\mathrm{G}$ \\
$\mathrm{Si}$ & 3 & 14 & $\mathrm{G}$ & 28 & $28-\mathrm{G}$ \\
$\mathrm{P}$ & 3 & 15 & $\mathrm{G}$ & 31 & $31-\mathrm{G}$ \\
$\mathrm{S}$ & 3 & 16 & $\mathrm{G}$ & 32 & $32-\mathrm{G}$ \\
$\mathrm{Ci}$ & 3 & 17 & $\mathrm{G}$ & 36 & $36-\mathrm{G}$ \\
$\mathrm{Ar}$ & 3 & 18 & $\mathrm{G}$ & 40 & $40-\mathrm{G}$ \\
$\mathrm{K}$ & 4 & 1 & $\mathrm{G}+18$ & 39 & $39-(\mathrm{G}+18)$ \\
$\mathrm{Ca}$ & 4 & 2 & $\mathrm{G}+18$ & 40 & $40-(\mathrm{G}+18)$
\end{tabular}




$\begin{array}{llllll}\mathrm{Sc} & 4 & 3 & \mathrm{G}+18 & 45 & 45-(\mathrm{G}+18) \\ \mathrm{Ti} & 4 & 4 & \mathrm{G}+18 & 48 & 48-(\mathrm{G}+18) \\ \mathrm{V} & 4 & 5 & \mathrm{G}+18 & 51 & 51-(\mathrm{G}+18) \\ \mathrm{Cr} & 4 & 6 & \mathrm{G}+18 & 52 & 52-(\mathrm{G}+18) \\ \mathrm{Mn} & 4 & 7 & \mathrm{G}+18 & 55 & 55-(\mathrm{G}+18) \\ \mathrm{Fe} & 4 & 8 & \mathrm{G}+18 & 56 & 56-(\mathrm{G}+18) \\ \mathrm{Co} & 4 & 9 & \mathrm{G}+18 & 59 & 59-(\mathrm{G}+18) \\ \mathrm{Ni} & 4 & 10 & \mathrm{G}+18 & 59 & 59-(\mathrm{G}+18) \\ \mathrm{Cu} & 4 & 11 & \mathrm{G}+18 & 64 & 64-(\mathrm{G}+18) \\ \mathrm{Zn} & 4 & 12 & \mathrm{G}+18 & 65 & 65-(\mathrm{G}+18) \\ \mathrm{Ga} & 4 & 13 & \mathrm{G}+18 & 70 & 70-(\mathrm{G}+18) \\ \mathrm{Ge} & 4 & 14 & \mathrm{G}+18 & 73 & 73-(\mathrm{G}+18) \\ \mathrm{As} & 4 & 15 & \mathrm{G}+18 & 75 & 75-(\mathrm{G}+18) \\ \mathrm{Se} & 4 & 16 & \mathrm{G}+18 & 79 & 79-(\mathrm{G}+18)\end{array}$

* Mass Number is rounded to the nearest whole number

**Number of Neutrons $=$ (Mass Number) - (Atomic Number)

$\wedge$ Most Hydrogen atoms consist of just one proton and one electron, but some also have one or two neutrons.

\begin{tabular}{|c|c|c|c|c|c|}
\hline $\mathrm{Kr}$ & 4 & 18 & $G+18$ & 85 & $85-(G+18)$ \\
\hline $\mathrm{Rb}$ & 5 & 1 & $\mathrm{G}+36$ & 86 & $85-(G+36)$ \\
\hline $\mathrm{Sr}$ & 5 & 2 & $\mathrm{G}+36$ & 88 & $88-(G+36)$ \\
\hline$Y$ & 5 & 3 & $G+36$ & 89 & $89-(G+36)$ \\
\hline $\mathrm{Zr}$ & 5 & 4 & $G+36$ & 91 & $91-(G+36)$ \\
\hline $\mathrm{Nb}$ & 5 & 5 & $\mathrm{G}+36$ & 93 & $93-(G+36)$ \\
\hline Mo & 5 & 6 & $\mathrm{G}+36$ & 96 & $96-(G+36)$ \\
\hline Tc & 5 & 7 & $\mathrm{G}+36$ & 99 & $99-(G+36)$ \\
\hline $\mathrm{Ru}$ & 5 & 8 & $\mathrm{G}+36$ & 101 & $101-(G+36)$ \\
\hline $\mathrm{Rh}$ & 5 & 9 & $G+36$ & 103 & $103-(G+36)$ \\
\hline $\mathrm{Pd}$ & 5 & 10 & $\mathrm{G}+36$ & 106 & $106-(G+36)$ \\
\hline $\mathrm{Ag}$ & 5 & 11 & $\mathrm{G}+36$ & 108 & $108-(G+36)$ \\
\hline $\mathrm{Cd}$ & 5 & 12 & $\mathrm{G}+36$ & 112 & $112-(G+36)$ \\
\hline In & 5 & 13 & $\mathrm{G}+36$ & 115 & $115-(G+36)$ \\
\hline Sn & 5 & 14 & $\mathrm{G}+36$ & 119 & $119-(\mathrm{G}+36)$ \\
\hline $\mathrm{Sb}$ & 5 & 15 & $\mathrm{G}+36$ & 122 & $122-(G+36)$ \\
\hline $\mathrm{Te}$ & 5 & 16 & $\mathrm{G}+36$ & 128 & $128-(G+36)$ \\
\hline 1 & 5 & 17 & $\mathrm{G}+36$ & 127 & $127-(G+36)$ \\
\hline $\mathrm{Xe}$ & 5 & 18 & $G+36$ & 131 & $131-(G+36)$ \\
\hline Cs & 6 & 1 & $G+54$ & 133 & $131-(G+54)$ \\
\hline $\mathrm{Ba}$ & 6 & 2 & $G+54$ & 137 & $137-(G+54)$ \\
\hline $\mathrm{La}$ & $6^{\wedge}$ & $3^{\wedge}$ & $G+54$ & 139 & $139-(G+54)$ \\
\hline $\mathrm{Ce}$ & $6^{\wedge}$ & $4^{\wedge}$ & $G+54$ & 140 & $140-(G+54)$ \\
\hline $\operatorname{Pr}$ & $6^{\wedge}$ & $5^{\wedge}$ & $G+54$ & 141 & $141-(G+54)$ \\
\hline $\mathrm{Nd}$ & $6^{\wedge}$ & $6^{\wedge}$ & $G+54$ & 144 & $144-(G+54)$ \\
\hline $\mathrm{Pm}$ & $6^{\wedge}$ & $7^{\wedge}$ & $\mathrm{G}+54$ & 145 & $145-(G+54)$ \\
\hline $\mathrm{Sm}$ & $6^{\wedge}$ & $8^{\wedge}$ & $G+54$ & 150 & $150-(G+54)$ \\
\hline $\mathrm{Eu}$ & $6^{\wedge}$ & $9^{\wedge}$ & $\mathrm{G}+54$ & 152 & $152-(G+54)$ \\
\hline Gd & $6^{\wedge}$ & $10^{\wedge}$ & $\mathrm{G}+54$ & 157 & $157-(G+54)$ \\
\hline $\mathrm{Tb}$ & $6^{\wedge}$ & $11^{\wedge}$ & $G+54$ & 159 & $159-(G+54)$ \\
\hline Dy & $6^{\wedge}$ & $12^{\wedge}$ & $G+54$ & 163 & $163-(G+54)$ \\
\hline $\mathrm{Ho}$ & $6^{\wedge}$ & $13^{\wedge}$ & $G+54$ & 165 & $165-(G+54)$ \\
\hline $\mathrm{Er}$ & $6^{\wedge}$ & $14^{\wedge}$ & $G+54$ & 167 & $167-(G+54)$ \\
\hline $\mathrm{Tm}$ & $6^{\wedge}$ & $15^{\wedge}$ & $\mathrm{G}+54$ & 169 & $169-(G+54)$ \\
\hline $\mathrm{Yb}$ & $6^{\wedge}$ & $16^{\wedge}$ & $G+54$ & 173 & $173-(G+54)$ \\
\hline $\mathrm{Lu}$ & $6^{\wedge}$ & $17^{\wedge}$ & $\mathrm{G}+54$ & 175 & $175-(G+54)$ \\
\hline \multirow{2}{*}{\multicolumn{6}{|c|}{$\begin{array}{l}{ }^{*} \text { Mass Number is rounded to the nearest whole number } \\
{ }^{\star *} \text { Number of Neutrons = (Mass Number) - (Atomic Number) }\end{array}$}} \\
\hline & & & & & \\
\hline \multicolumn{6}{|c|}{ ^ Lanthanide elements } \\
\hline $\mathrm{Hf}$ & 6 & 4 & $\mathrm{G}+68$ & 178 & $178-(G+68)$ \\
\hline $\mathrm{Ta}$ & 6 & 5 & $\mathrm{G}+68$ & 181 & $181-(G+68)$ \\
\hline
\end{tabular}




\begin{tabular}{|c|c|c|c|c|c|}
\hline W & 6 & 6 & $G+68$ & 184 & $184-(G+68)$ \\
\hline $\mathrm{Re}$ & 6 & 7 & $\mathrm{G}+68$ & 186 & $186-(\mathrm{G}+68)$ \\
\hline Os & 6 & 8 & $\mathrm{G}+68$ & 190 & $190-(\mathrm{G}+68)$ \\
\hline Ir & 6 & 9 & $G+68$ & 192 & $192-(\mathrm{G}+68)$ \\
\hline $\mathrm{Pt}$ & 6 & 10 & $\mathrm{G}+68$ & 195 & $195-(G+68)$ \\
\hline $\mathrm{Au}$ & 6 & 11 & $\mathrm{G}+68$ & 197 & $197-(\mathrm{G}+68)$ \\
\hline $\mathrm{Hg}$ & 6 & 12 & $\mathrm{G}+68$ & 201 & $201-(\mathrm{G}+68$ \\
\hline $\mathrm{Ti}$ & 6 & 13 & $\mathrm{G}+68$ & 204 & $204-(G+68$ \\
\hline $\mathrm{Pb}$ & 6 & 14 & $\mathrm{G}+68$ & 207 & $207-(\mathrm{G}+68$ \\
\hline $\mathrm{Bi}$ & 6 & 15 & $\mathrm{G}+68$ & 209 & $209-(G+68)$ \\
\hline Po & 6 & 16 & $\mathrm{G}+68$ & 209 & $209-(G+68)$ \\
\hline At & 6 & 17 & $\mathrm{G}+68$ & 210 & $210-(\mathrm{G}+68)$ \\
\hline $\mathrm{Rn}$ & 6 & 18 & $\mathrm{G}+68$ & 222 & $222-(G+68)$ \\
\hline $\mathrm{Fr}$ & 7 & 1 & $\mathrm{G}+86$ & 223 & $123-(\mathrm{G}+86)$ \\
\hline $\mathrm{Ra}$ & 7 & 2 & $\mathrm{G}+86$ & 226 & $226-(G+86)$ \\
\hline$A C$ & $7^{\wedge}$ & $3^{\wedge}$ & $\mathrm{G}+86$ & 227 & $227-(G+86)$ \\
\hline Th & $7^{\wedge}$ & $4^{\wedge}$ & $\mathrm{G}+86$ & 232 & $232-(G+86)$ \\
\hline $\mathrm{Pa}$ & $7^{\wedge}$ & $5^{\wedge}$ & $\mathrm{G}+86$ & 231 & $231-(G+86)$ \\
\hline$U$ & $7^{\wedge}$ & $6^{\wedge}$ & $\mathrm{G}+86$ & 238 & $238-(\mathrm{G}+86$ \\
\hline $\mathrm{Np}$ & $7^{\wedge}$ & $7^{\wedge}$ & $\mathrm{G}+86$ & 237 & $237-(G+86$ \\
\hline $\mathrm{Pu}$ & $7^{\wedge}$ & $8^{\wedge}$ & $\mathrm{G}+86$ & 244 & $244-(G+86)$ \\
\hline Am & $7^{\wedge}$ & $9^{\wedge}$ & $\mathrm{G}+86$ & 243 & $243-(\mathrm{G}+86)$ \\
\hline $\mathrm{Cm}$ & $7^{\wedge}$ & $10^{\wedge}$ & $\mathrm{G}+86$ & 247 & $247-(G+86)$ \\
\hline $\mathrm{Bk}$ & $7^{\wedge}$ & $11^{\wedge}$ & $\mathrm{G}+86$ & 247 & $247-(G+86)$ \\
\hline $\mathrm{Cf}$ & $7^{\wedge}$ & $12^{\wedge}$ & $\mathrm{G}+86$ & 251 & $251-(G+8$ \\
\hline Es & $7^{\wedge}$ & $13^{\wedge}$ & $\mathrm{G}+86$ & 254 & $254-(G+8$ \\
\hline $\mathrm{Fm}$ & $7^{\wedge}$ & $14^{\wedge}$ & $\mathrm{G}+86$ & 257 & $257-(\mathrm{G}+86)$ \\
\hline Md & $7^{\wedge}$ & $15^{\wedge}$ & $\mathrm{G}+86$ & 258 & $258-(G+86$ \\
\hline No & $7^{\wedge}$ & $16^{\wedge}$ & $\mathrm{G}+86$ & 259 & $259-(G+86)$ \\
\hline Lr & $7^{\wedge}$ & $17^{\wedge}$ & $\mathrm{G}+86$ & 262 & $262-(G+86$ \\
\hline
\end{tabular}

* Mass Number is rounded to the nearest whole number

${ }^{* *}$ Number of Neutrons $=($ Mass Number $)-($ Atomic Number $)$

$\wedge$ Actinide elements

\begin{tabular}{|c|c|c|c|c|c|}
\hline $\mathrm{Rf}$ & 7 & 4 & $G+100$ & 261 & $261-(\mathrm{G}+100)$ \\
\hline $\mathrm{Db}$ & 7 & 5 & $G+100$ & 262 & $262-(G+100)$ \\
\hline $\mathrm{Sg}$ & 7 & 6 & $\mathrm{G}+100$ & 266 & $266-(\mathrm{G}+100)$ \\
\hline $\mathrm{Bh}$ & 7 & 7 & $G+100$ & 264 & $264-(G+100)$ \\
\hline $\mathrm{Hs}$ & 7 & 8 & $G+100$ & 277 & $277-(\mathrm{G}+100)$ \\
\hline Mt & 7 & 9 & $G+100$ & 268 & $268-(G+100)$ \\
\hline Ds & 7 & 10 & $G+100$ & 271 & $271-(G+100)$ \\
\hline $\mathrm{Rg}$ & 7 & 11 & $G+100$ & 272 & $272-(G+100)$ \\
\hline $\mathrm{Cn}$ & 7 & 12 & $\mathrm{G}+100$ & 277 & $277-(G+100)$ \\
\hline $\mathrm{Nh}$ & 7 & 13 & $G+100$ & 284 & $284-(G+100)$ \\
\hline $\mathrm{Fl}$ & 7 & 14 & $G+100$ & 289 & $289-(G+100)$ \\
\hline Mc & 7 & 15 & $G+100$ & 288 & $288-(G+100)$ \\
\hline Lv & 7 & 16 & $G+100$ & 293 & $293-(\mathrm{G}+100)$ \\
\hline Ts & 7 & 17 & $G+100$ & 294 & $294-(\mathrm{G}+100)$ \\
\hline $\mathrm{Og}$ & 7 & 18 & $G+100$ & 294 & $294-(G+100)$ \\
\hline $\mathrm{F}^{\wedge}$ & 8 & 1 & $G+118$ & 299.4045516\# & $299-(G+118)$ \\
\hline $\mathrm{F}^{\wedge}$ & 8 & 2 & $\mathrm{G}+118$ & 304.9082988\# & $305-(G+118)$ \\
\hline $\mathrm{F}^{\wedge}$ & 8 & 3 & $\mathrm{G}+118$ & 310.5049244\# & $310-(\mathrm{G}+118)$ \\
\hline $\mathrm{F}^{\wedge}$ & 8 & 4 & $G+118$ & $316.2127221 \#$ & $316-(\mathrm{G}+118)$ \\
\hline $\mathrm{F}^{\wedge}$ & 8 & 5 & $G+118$ & $322.0250960 \#$ & $322-(G+118)$ \\
\hline $\mathrm{F}^{\wedge}$ & 8 & 6 & $G+118$ & 328.0965222\# & $328-(G+118)$ \\
\hline $\mathrm{F}^{\wedge}$ & 8 & 7 & $G+118$ & 334.1276941\# & $334-(G+118)$ \\
\hline $\mathrm{F}^{\wedge}$ & 8 & 8 & $G+118$ & 340.2697329\# & $340-(G+118)$ \\
\hline $\mathrm{F}^{\wedge}$ & 8 & 9 & $G+118$ & 346.5246766\# & $346-(G+118)$ \\
\hline $\mathrm{F}^{\wedge}$ & 8 & 10 & $G+118$ & 352.8946010\# & $353-(G+118)$ \\
\hline $\mathrm{F}^{\wedge}$ & 8 & 11 & $G+118$ & 359.3816189\# & $359-(G+118)$ \\
\hline $\mathrm{F}^{\wedge}$ & 8 & 12 & $G+118$ & 363.4081821\# & $363-(\mathrm{G}+118)$ \\
\hline $\mathrm{F}^{\wedge}$ & 8 & 13 & $G+118$ & 367.4798598\# & $367-(\mathrm{G}+118)$ \\
\hline $\mathrm{F}^{\wedge}$ & 8 & 14 & $G+118$ & 371.5971555\# & $372-(G+118)$ \\
\hline $\mathrm{F}^{\wedge}$ & 8 & 15 & $\mathrm{G}+118$ & 375.7605822\# & $376-(\mathrm{G}+118)$ \\
\hline$F^{\wedge}$ & 8 & 16 & $\mathrm{G}+118$ & 379.9706577\# & $380-(\mathrm{G}+118)$ \\
\hline$F^{\wedge}$ & 8 & 17 & $G+118$ & 384.2279022\# & $384-(G+118)$ \\
\hline $\mathrm{F}^{\wedge}$ & 8 & 18 & $\mathrm{G}+118$ & $388.5328466 \#$ & $389-(G+118)$ \\
\hline $\mathrm{F}^{\wedge}$ & 9 & 1 & $G+136$ & $392.8860233 \#$ & $393-(G+136)$ \\
\hline \multicolumn{6}{|c|}{$\begin{array}{l}\text { Mass Number is rounded to the nearest whole number. } \\
\text { *Number of Neutrons }=\text { (Mass Number) - (Atomic Number) } \\
\text { A : Future elements aligned down element Ac, and possibly starting from P8 \& G3, till P11 \& G14 } \\
: \text { As depicted in Figure } 2\end{array}$} \\
\hline
\end{tabular}




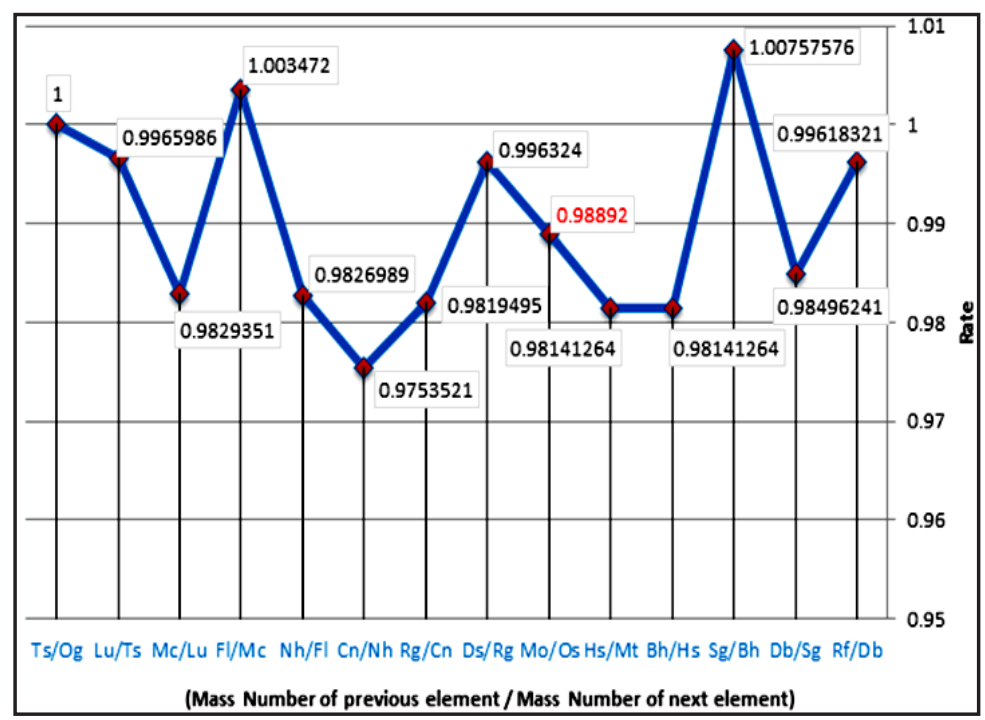

Fig. 2. The average of the ratio of the Mass Number of previous element/The Mass Number of the next element, which are built on a leaner chain of 15 elements, (from element Rf till Og), located in period 7 and groups from 4 till 18 in the periodic table

As depicted in Table 2, the average of the ratio of (Mass Number of previous element/The Mass Number of the next element), located in period 7 and groups from 4 till 18 in the periodic table indicated a ratio of $(0.98892)$ peaks related to the Mass numbers of these 15 elements, which are built on a leaner chain of elements starting from element Rf till $\mathrm{Og}$.

\section{Key findings}

Throughout this paper, elements positions were described according to period and groups numbers in the periodic table. Period and group's numbers used to determine the Atomic Number and Neutrons Numbers to any elements, through which 17 formulas were produced. Therefore it can be concluded that determining the Atomic Numbers and Neutrons Numbers to any elements, are directly linked to the numbers of period and group in the periodic table. Results showed that there is only a rate of $0.084 \%$ of obtained formulas with period numbers can be used to determine the Atomic Numbers and then the Neutrons Numbers, whereas the majority of $99.91 \%$ depended on group's numbers to be used in formulas to determine the Atomic numbers and the Neutrons Numbers. The findings from this study suggest that only 10 elements the periodic table, (from $\mathrm{H}$ till $\mathrm{Ne}$ ), used formulas with period members, whereas majority of 108 elements only needed to use numbers of group in their formulas. These results would seem to suggest that the Atomic Number, Electrons Number and Neutrons Numbers of elements have been successfully calculated by these formulas. Correspondingly, these leaner formulas were usefully implemented to predict the Atomic Number, Mass Number and Neutrons Numbers of the future elements. The results of this study shown that average of the obtained ratio (0.98892) of elements from $\mathrm{Rf}$ till $\mathrm{Og}$ has no significant change on the amount of Mass Number produced in this one period (number 7). Therefore it can be concluded that the sample of next 19 elements after Og may will have their Mass numbers and then the Neutrons Numbers by the similar leaner ratio, as depicted in Fig. 2 and Table 2.

\section{CONCLUSION}

The periodic table plays a critical role in the teaching and learning of chemistry. Since its inception, the form of the periodic table is proposed as its fundamental graphic representation. This idea is easily obtained from the linear succession of the elements when they are ranged in groups and periods by growing atomic number in IUPAC's two- dimensional table. In this research, the period and group numbers were used to produce formulas to determine the Atomic Number, and Neutrons Numbers to 118 elements in the periodic table. Therefore it can be concluded that despite common methods for calculation and determination, here are some simples and regulatory formulas which control 
levels of active calculation ways among the Mass Number, Atomic Number, and Neutrons Numbers. In shortage of similar implications, such simple formulas may play a critical role in the teaching and learning of chemistry. Researching atomic coding formulas for the elements will be accumulated by present research group. Thus, the originality of this research will become more apparent by identifying the results of this study shown that location of elements at the periods and groups have significant role on produce simple layouts of formulas to determine the amount of Atomic Number as well as the Mass and Neutrons Numbers in the periodic table. Another possible area of future research would be to investigate why the 17 modifications of the conventional calculations are practically fitted with the 19 future elements which provide important insights into a new horizon to the future researches.

\section{ACKNOWLEDGMENT}

For advice, help and support of various kinds, I should like to thank Angham M. Saleh, Noor, Nada and Fatima. Thank goes too to the University of Thi-qar, College of Engineering/ Iraq.

\section{Conflict of Interest}

The authors declare that they have no conflict of interest.

\section{REFERENCES}

1. Bent, H. A., Weinhold, F. ;Supporting information: News from the periodic table: An introduction to Periodicity symbols, tables, and models for higher-order valency and donor-acceptor kinships., 2007, 1-17.

2. Ben-Zvi, N., \& Genut, S. ;Uses and limitations of scientific models: The periodic table as an inductive tool. International Journal of Science Education., 1998, 20(3), 351-360.

3. Gorin,G. Mendeleev and Moseley: The principal discoverers of the periodic law. Journal of Chemical Education., 1996, 73(6), 490-493.

4. Gordin, M. D.. A well-ordered thing: Dmitrii Mendeleev and the shadow of the periodic table. New York: Basic Books., 2004, 52-60.

5. Hinrichs, G. D. ;On the classification and the atomic weights of the so-called chemical elements, with particular reference to Stas's determinations. Proceedings of the American Association for the Advancement of Science., 2017, 18(5), 112-124. Archived from the original on 2 August, 2017.

6. IUPAC. ;IUPAC Periodic Table of the Elements" (PDF). iupac.org. IUPAC. Archived (PDF) from the original on 22 August., 2015, 11-58.

7. Kaji, M. ;Discovery of the periodic law: Mendeleev and other researchers on element classification in the 1860s. In Rouvray, D. H.; King, R. Bruce. The periodic table: Into the 21st Century. Research Studies Press., 2004, 91-122 (95). ISBN 0-86380-292-3.

8. Karol, P. J."The Mendeleev-Seaborg periodic table: Through $\mathrm{Z}=1138$ and beyond". Journal of Chemical Education., 2002, 79(1), 60-63.

9. Koppenol,W.H. ;Naming of New Elements (IUPAC Recommendations 2002) ;(PDF). Pure and Applied Chemistry., 2002, 74 (5):787791. doi:10.1351/pac200274050787.

10. McMurry, J., \& Fay, R. C. Chemistry (3rd ed.). Upper Saddle River, NJ:Prentice Hall. Mendeleev, D.(1879). The periodic law of the chemical elements. The Chemical News., 2001, 40, 1042.

11. Niaz, M., Rodríguez, M.A., \& Brito, A. An appraisal of Mendeleev's contribution to the development of the periodic table. Studies in History and Philosophy of Science., 2004, 35, 271-282.

12. Orlando: Holt, Rinehart \& Winston Chang R. Essential Chemistry, Boston: McGraw-Hill., 2000, 2, 73-74.

13. Siegfried, R. From elements to atoms a history of chemical composition. Philadelphia, Pennsylvania:Library of Congress Cataloging-inPublication Data., 2002. 92. ISBN 0-87169-924-9.

14. Silberberg, M. S.Chemistry: The molecular nature of matter and change (4th ed.). New York: McGraw-Hill., 2006, 536, ISBN 0-07-111658-3.

15. Russo, S., \& Silver, M. Introductory chemistry (2nd ed.). San Francisco: Benjamin Cummings., 2002, 33-74. 